\title{
GMR
}

\section{Tobacco serine/threonine protein kinase gene NrSTK enhances black shank resistance}

\author{
Y.-L. Gao, B.-W. Wang, Z.-L. Xu, M.-Y. Li, Z.-B. Song, W.-Z. Li and Y.-P. Li \\ Tobacco Breeding and Biotechnology Research Center, \\ Yunnan Academy of Tobacco Agricultural Sciences, \\ Key Laboratory of Tobacco Biotechnological Breeding, \\ National Tobacco Genetic Engineering Research Center, Kunming, China \\ Corresponding authors: Y.-P. Li \\ E-mail: liyongping@yntsti.com \\ Genet. Mol. Res. 14 (4): 16415-16424 (2015) \\ Received July 26, 2015 \\ Accepted October 20, 2015 \\ Published December 9, 2015 \\ DOI http://dx.doi.org/10.4238/2015.December.9.11
}

ABSTRACT. A serine/threonine protein kinase gene (NrSTK) was cloned from Nicotiana repanda based on the sequence of a previously isolated resistance gene analog $(R G A)$. Expression of $R G A$ was induced by challenge with the pathogen black shank. The NrSTK gene was predicted to encode a protein kinase that contained an ATP binding site at residues 41-69 and a serine/threonine protein kinase activation sequence spanning the region 161-173. Overexpression of NrSTK in the susceptible tobacco variety Honghuadajinyuan significantly enhanced resistance to black shank, indicating that NrSTK plays a role in incompatibility reactions between tobacco and the pathogen. Characterization of NrSTK will help elucidate the molecular mechanisms involved in black shank resistance in N. repanda.

Key words: Tobacco; Serine/threonine protein kinase; Black shank; Resistance 


\section{INTRODUCTION}

Receptor kinases are important receptors of key molecules in signaling pathways. These kinases belong to multiple gene families that play critical roles in the recognition and transduction of extracellular signals. For instance, receptor kinases in plants participate in a diverse range of physiological and biochemical processes triggered by plant hormones and environmental cues, including self-incompatibility, regulation of endosperm and pollen development, flower shedding, response to brassinosteroid and environmental stresses, and plant disease resistance (Morris and Walker, 2003; Morillo and Tax, 2006). Serine/threonine protein kinases (STKs) are receptor proteins that mediate signal transduction in plant defense responses. During plant and microbe interactions, STKs are mainly involved in the recognition and transduction of pathogen-derived signals. A number of STK resistance genes have been cloned from a wide range of plant species, such as Pto and Prf from tomato (Martin et al., 1993; Salmeron et al., 1996), Xa21 from rice (Song et al., 1995), RPS5 and PBS1 from Arabidopsis (Warren et al., 1998; Swiderski and Innes, 2001), and Rpg5 from barley (Brueggeman et al., 2008). As STK motifs are conserved across different plant species, these sequences have been used to identify and clone many genes containing an STK motif from diverse plant species (Vallad et al., 2001; Deng and Gmitter, 2003; Di Gaspero and Cipriani, 2003).

The tobacco disease black shank is caused by the fungus Phytophthora parasitica var. nicotianae. To date, four physiological races of the fungal pathogen have been identified (races $0,1,2,3)$. Races 0 and 1 are the most common in tobacco-growing regions of China, with the former being predominant. Black shank is one of most devastating diseases of tobacco production and occurs in almost every tobacco-growing province in China. Investigations into the molecular interactions between tobacco and $P$. parasitica var. nicotianae have been undertaken. It was shown that rapid accumulation of transcripts of a lipoxygenase $(L O X)$ gene occur after the initial challenge by the pathogen, indicating that LOX may play a role in black shank resistance (Rance et al., 1998).

Resistance testing has established that wild type tobacco $N$. repanda is immune to black shank disease; this species is therefore a valuable genetic resource for improving black shank resistance in cultivated tobacco. However, hybrid incompatibility among $N$. repanda and cultivated tobacco varieties has made it difficult to achieve the transfer of resistance into cultivated tobacco by standard crosses. In this study, we identified and cloned the NrSTK gene from N. repanda, and transgenic experiments showed that NrSTK was capable of conferring black shank resistance in a susceptible commercial variety.

\section{MATERIAL AND METHODS}

\section{Plant materials and inoculation}

$N$. repanda plants were grown in the greenhouse; seedlings at about the 5-leaf stage were inoculated with the pathogen $P$. parasitica var. nicotianae according to the procedure of Gao et al. (2010).

\section{Cloning and analysis of NrSTK}

Plant roots were collected 9 days after inoculation with $P$. parasitica var. nicotianae and used for extracting total RNA using a Trizol reagent kit (Invitrogen, USA). Genomic DNA contamination 
of the RNA samples was removed using the PrimeScript RT reagent kit with gDNA Eraser (Takara, Japan) prior to cDNA synthesis. Primers used for RACE (rapid amplification of cDNA ends) were based on sequences of a previously cloned gene fragment RGA18 (Gao et al., 2010). The 3'RACE primers were 3'RGA18GSP1 (5'-GTTTACTCGTTCGGTGTTGT-3') and 3RGA18GSP2 (5'-GAATGGGCAATGAAGAAGAC-3') and the 5'RACE primers were 5'RGA18GSP1 (5'-AGATGC GGATGGTGGAACTG-3') and 5'RGA18GSP2 (5'-AAGACCTTGTCGGGACTCAG-3'). The 5' and 3 ' ends of NrSTK cDNA were cloned using the 3'-Full RACE Core Set Ver2.0 and a 5'-Full RACE Kit (Takara, Japan), respectively. Assembly of full-length NrSTK was performed with DNAstar software and manual removal of vector sequences. The open reading frame (ORF) of NrSTK was determined by ORF finder (http://www.ncbi.nlm.nih.gov/projects/gorf/) and the protein product was predicted by DNAstar translation. The molecular weight and isoelectric point of the predicted protein were obtained using the Expasy pl/Mw program (http://us.expasy.org/tools/pi_tool.html); conserved motifs were identified using the ScanProsite program (http://www.expasy.org/tools/ scanprosite/); and protein subcellular location was predicted with ProtComp Version 6 (http:// linux1.softberry.com/berry.phtml?) and WoLF PSORT (http://wolfpsort.org/). Transmembrane regions were predicted with TMpred (http://www.ch.embnet.org/software/TMPRED_form.html). Multiple sequence alignments were conducted with Clustal $x$ software and the results were edited using GeneDoc software (Nicholas et al., 1997). Phylogenetic trees were constructed with MEGA4 (Tamura et al., 2013).

\section{Vector construction}

The following primers were used to amplify NrSTK cDNA: NrSTKF, CGCGGATCCATAACT ATCCAAAGTCCCCC (BamHI site underlined) and NrSTKR, GGGGAGCTCCCTAAGGACAGTCT GTACCG (Sacl site underlined). Reactions were performed in a $50-\mu \mathrm{L}$ volume containing $200 \mathrm{ng}$ cDNA, 1X Phusion HF reaction buffer, 10 mM dNTP, 2 U Phusion High-Fidelity DNA Polymerase, 1 $\mu \mathrm{M}$ primers. $\mathrm{PCR}$ was performed using a Mastercycler pro (Eppendorf, Germany) with the following parameters: $98^{\circ} \mathrm{C}$ for $30 \mathrm{~s}$, followed by 35 cycles of $98^{\circ} \mathrm{C}$ for $10 \mathrm{~s}, 60^{\circ} \mathrm{C}$ for $20 \mathrm{~s}, 72^{\circ} \mathrm{C}$ for 45 $\mathrm{s}$, and a final step of $72^{\circ} \mathrm{C}$ for $7 \mathrm{~min}$. PCR products were cloned into the TOPO vector (Invitrogen, USA) and then sequenced. The NrSTK gene was released by digesting NrSTK-containing TOPO vector with BamHI and Sacl. The recovered NrSTK of about 1100 bp was cloned into the BamHI and Sacl sites of pBI121 to generate the expression vector $p B / 121-N r S T K$.

\section{Tobacco transformation and genomic PCR analysis}

The expression vector $p B 1121-N r S T K$ was introduced into Agrobacterium GV3101 using the freeze-thaw method. The leaf disc method was employed to transform the tobacco black shank susceptible variety Honghuadajinyuan. Primers targeting the CaMV35s promoter (35SF, 5-ATGGT TAGAGAGGCTTACGC-3; 35SR, 5-CACATCAATCCACTTGCTTT-3), and the NPT // gene (NPT IIF, 5-TCGGCTATGACTGGGCACAACAGA-3; NPT IIR, 5-AAGAAGGCGATAGAAGGCGATGCG -3 ) were used to identify transgenic plants by PCR. Transgenic seedlings were grown to the 4-leaf stage, and about $100 \mathrm{mg}$ leaves were collected per plant. DNA was extracted using the DNeasy Plant Mini Kit Kit. PCR was performed in a $20-\mu \mathrm{L}$ volume containing $20 \mathrm{ng}$ CDNA with following conditions: $94^{\circ} \mathrm{C}$ for $5 \mathrm{~min}$, followed by 30 cycles of $94^{\circ} \mathrm{C}$ for $30 \mathrm{~s}, 56^{\circ} \mathrm{C}$ for $45 \mathrm{~s}, 72^{\circ} \mathrm{C}$ for $30 \mathrm{~s}$, and a final step of $72^{\circ} \mathrm{C}$ for $7 \mathrm{~min}$. 


\section{Evaluation of responses of transgenic lines to black shank pathogen}

Transgenic lines were evaluated for response to $P$. parasitica var. nicotianae infection using the procedure of Gao et al. (2010). The black shank susceptible variety Honghuadajinyuan and the moderate resistance variety Gexin 3 were used as controls. Statistical analysis of disease index values was carried out with commercially available statistical software (Data Processing System v14.50). The threshold of significance was defined as $P<0.01$. Disease severity was ranked on a scale from 0 to 9 (examining the performance of individual plants) based on the Chinese national standard for "Grade and Investigation Method of Tobacco Diseases and Insect Pests" (GB / T 23222-2008). The "GB/T 23222-2008" disease severity ranking is as follows: grade 0 , whole plant symptom free; grade 1 , stem lesion < $1 / 3$ of girth or <1/3 leaves wilting; grade 3 , stem lesions between $1 / 3$ and $1 / 2$ of girth or between $1 / 3$ and $1 / 2$ leaves slightly wilting; grade 5 , stem lesions $>1 / 2$ of girth, but not completely around girth, or between $1 / 2$ and $2 / 3$ of leaves wilting; grade 7 , stem lesions around whole girth or $>2 / 3$ of leaves wilting; and grade 9 , plants look dead. The disease index was estimated from the assigned disease grades. Disease severity was divided into 6 grades according to the disease index (reference GB / T 23222-2008): 1) highly resistant or immune (I), with disease index of 0 ; 2) resistant (R), with a disease index of 0.1 to 20 ; 3) moderately resistant (MR), with a disease index of 20.1 to $40 ; 4)$ moderately susceptible (MS), with a disease index of 40.1 to $60 ; 5$ ) susceptible (S), with a disease index of 60.1 to $80 ; 6$ ) highly susceptible (HS), with a disease index of 80.1 to 100 .

\section{Analyses of transgenic lines by RT-PCR and Northern blot}

At 15 days post-inoculation, transgenic plants were assessed for their disease state. The roots were than collected, rinsed in tap water, followed by three washes with distilled water, dried by filter paper, and frozen in liquid nitrogen, and maintained at $-80^{\circ} \mathrm{C}$ until use. Total RNA was isolated using a Trizol kit (Invitrogen, USA). First-strand cDNA synthesis was performed using the PrimeScript ${ }^{T M}$ First Strand cDNA Synthesis Kit (Takara, Japan). RT-PCR of NrSTK was performed using the primer pair: forward, GGAGAATGGGAACCTCAAGA and reverse, AATCATTGACTTGCGGAGA. An amplicon of 651 bp was produced. EF1a was used as the internal control and was amplified using the primer pair: forward, AGACCACCAAGTACTACTGCAC and reverse, CCACCAATCTTGTACACATCC. The amplification conditions were: $94^{\circ} \mathrm{C}$ for $2 \mathrm{~min}$, followed by 24 cycles of $94^{\circ} \mathrm{C}$ for $30 \mathrm{~s}, 55^{\circ} \mathrm{C}$ for $30 \mathrm{~s}$, and $72^{\circ} \mathrm{C}$ for $30 \mathrm{~s}$. For the northern blot analysis, $40 \mu \mathrm{g}$ total RNA was separated on a $2 \%$ formaldehyde agarose gel; this was blotted onto a positively charged nylon membrane, which was cross-linked by UV, and hybridized using an NrSTK cDNA probe labeled by the random primer labeling method (DIG DNA Labeling Kit, Roche, Germany). Prehybridization and hybridization was conducted at $65^{\circ} \mathrm{C}$ according to the instructions of the DIG High Prime DNA Labeling and Detection Starter Kit II (Roche, Germany).

\section{RESULTS}

\section{Cloning and sequence analysis of the full-length NrSTK cDNA}

The full-length NrSTK cDNA was isolated by 5'RACE and 3'RACE based on the sequence of RGA18 (Resistance gene analog); we cloned and sequenced RGA18 in an earlier study and 
showed it was induced by the black shank pathogen (Gao et al., 2010). Total RNA was extracted from $N$. repanda roots $9 \mathrm{~d}$ after exposure to $P$. parasitica var. nicotianae. As shown in Figure 1, a full-length cDNA was obtained with a predicted 1101 bp ORF in the region 226-1326 that encodes a deduced polypeptide of 366 amino acids. Expasy pl/Mw predicted a pl of 5.49 and a molecular weight of $40.83 \mathrm{kDa}$. ScanProsite searches for conserved motifs identified a kinase domain comprising residues 41 to 304 , a protein kinase ATP-binding signaling region from 41 to 69 , and a serine/threonine protein kinase activation signal region from 161 to 173 (Figure 2). The predicted amino acid sequence of NrSTK showed $68 \%$ identity and $78 \%$ similarity with the tomato serine/threonine protein kinase (Pto, GenBank accession No. AAB47421); sequence alignment is shown in Figure 2. Our analyses indicate that NrSTK encoded a serine/threonine protein kinase. NrSTK was predicted by ProtComp Version 6 and WoLF PSORT to be located in the cytoplasm and to contain a transmembrane region from residues 138 to 162 .

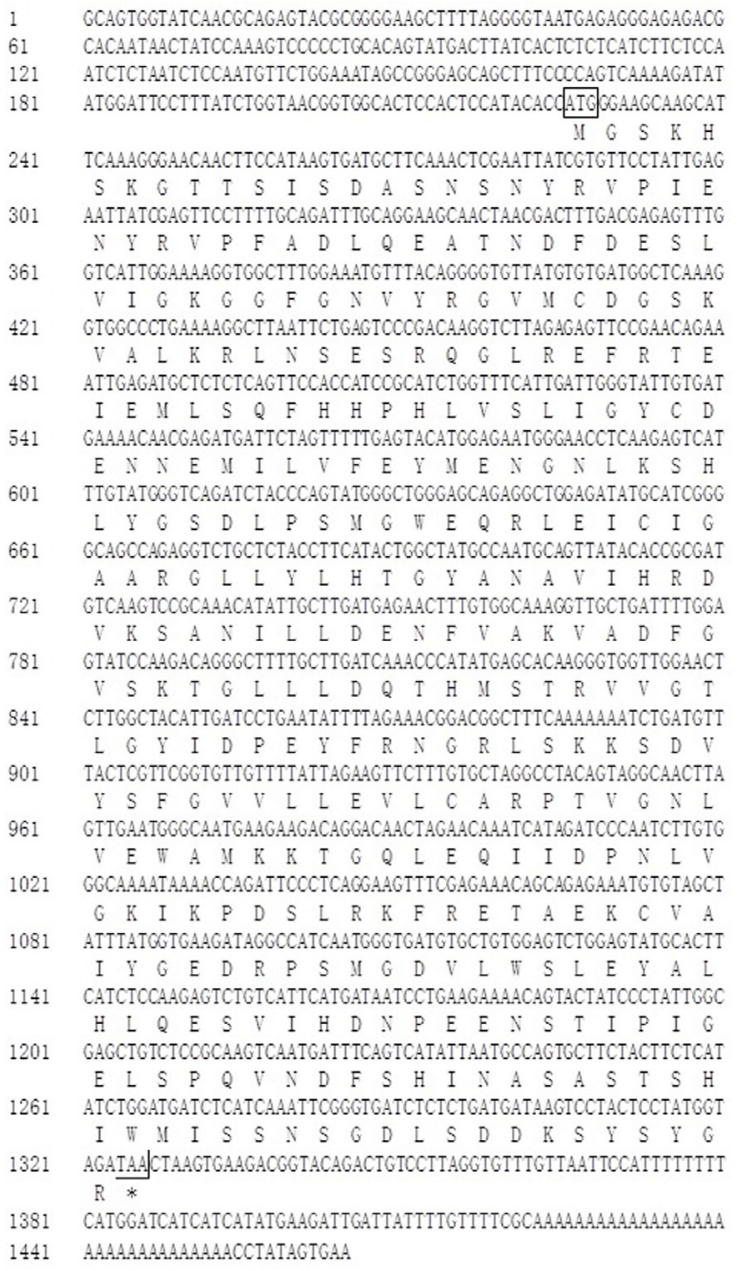

Figure 1. Full-length cDNA of NrSTK and deduced amino acid sequences. The start codon and termination codon was boxed. 


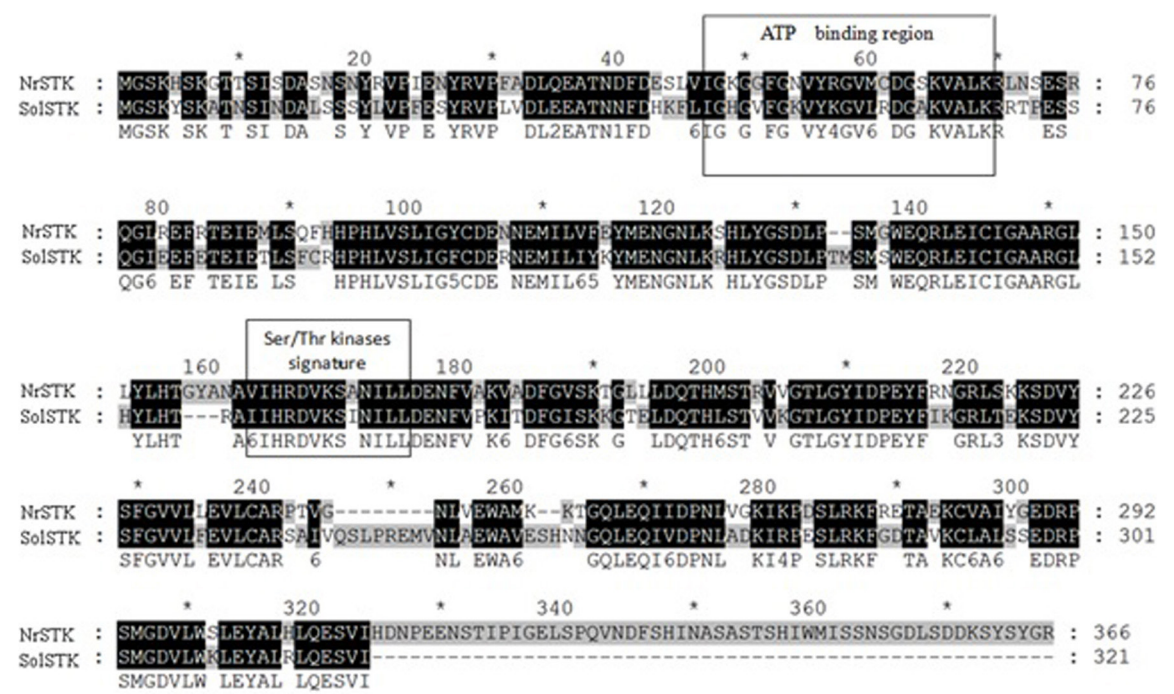

Figure 2. Alignment of the NrSTK deduced amino acid and tomato PTO. ATP binding region and Ser/Thr kinases signature were boxed.

Phylogenetic analyses of NrSTK and STKs of tomato, melon, Heuchera villosa, Arabidopsis, rapeseed, and rice indicated that NrSTK was most closely related to tomato SolSTK (Figure 3); this conclusion is consistent with the fact that both tobacco and tomato belong to the Solanaceae family.

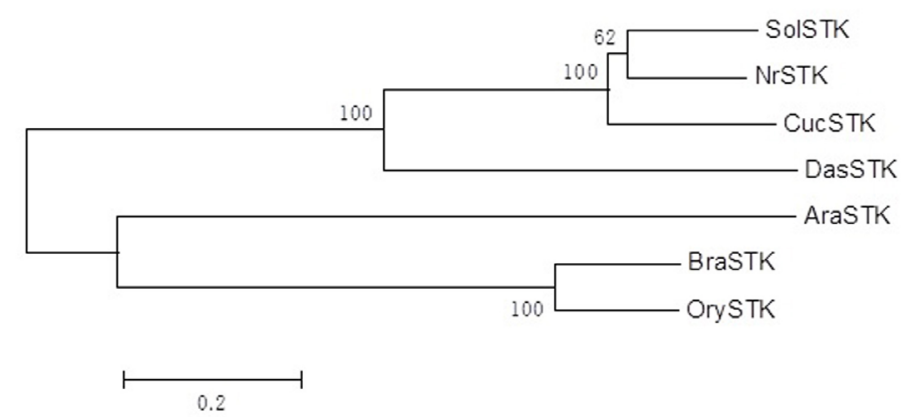

Figure 3. Phylogenetic analysis of NrSTK and STK from other plants containing tomato (SolSTK, AAB47421), melon (CucSTK, AF354500), Dasypyrum villosum (DasSTK, AEF30546), Arabidopsis (AraSTK, CAA48538), rape (BraSTK, AAA33004) and rice (OrySTK, AEF00939). Numbers on the branches represent bootstrap values (for 1000 replicates). The scale bar represents a branch length of 0.2 for amino acids.

\section{NrSTK confers tobacco black shank resistance}

To examine the possible function and role of NrSTK in tobacco black shank resistance, a vector overexpressing NrSTK was constructed and introduced to the susceptible tobacco variety Honghuadajinyuan by Agrobacterium-mediated transformation. Seven independent transgenic lines were generated and designated RLK22-1, RLK69-6, RLK72-6, RLK76-6, RLK78-3, RLK87-3, 
and RLK88-6. These transgenic lines were identified by genomic DNA PCR and electrophoretic analyses. All of the transgenic tobacco lines displayed the expected bands for the CaMV $35 \mathrm{~S}$ promoter and NPT // genes of $697 \mathrm{bp}$ and $750 \mathrm{bp}$, respectively (Figure 4).

The expression levels of NrSTK in the transgenic plants were determined by RT-PCR analysis. The RLK69-1, RLK87-3, and RLK88-6 lines displayed significantly higher expression levels of NrSTK than the susceptible variety Honghuadajinyuan; RLK88-6 showed the highest level of expression, while RLK22-1 was slightly higher than NrSTK (Figure 5). Northern blot analyses confirmed these results (Figure 6).

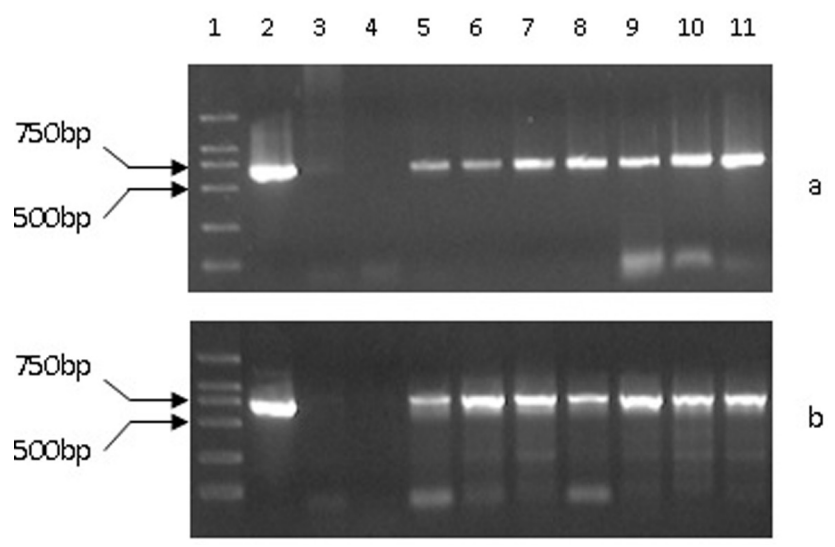

Figure 4. Analysis of transgenic lines by genomic PCR for 35S promoter (a) and NPTII gene (b). Lanes 1 to $11=$ marker DL2000, PBI121, Honghuadajinyuan, water, RLK22-1, RLK 69-6, RLK 72-6, RLK 76-6, RLK 78-3, RLK 87-3, RLK 88-6, respectively.

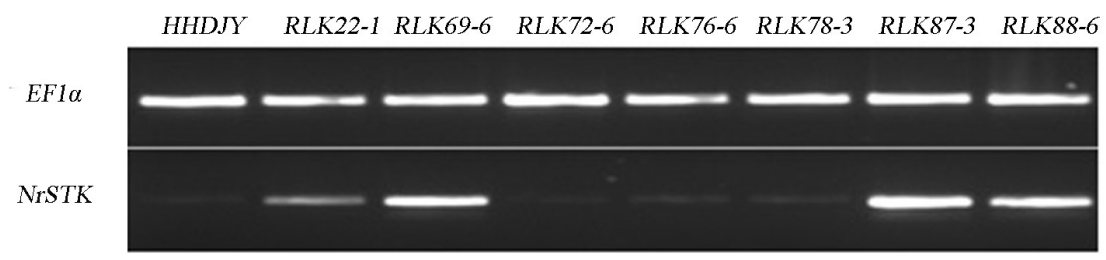

Figure 5. RT-PCR result of NrSTK gene expression in transgenic plants. EF1a control, HHDJY Honghuadajinyuan.

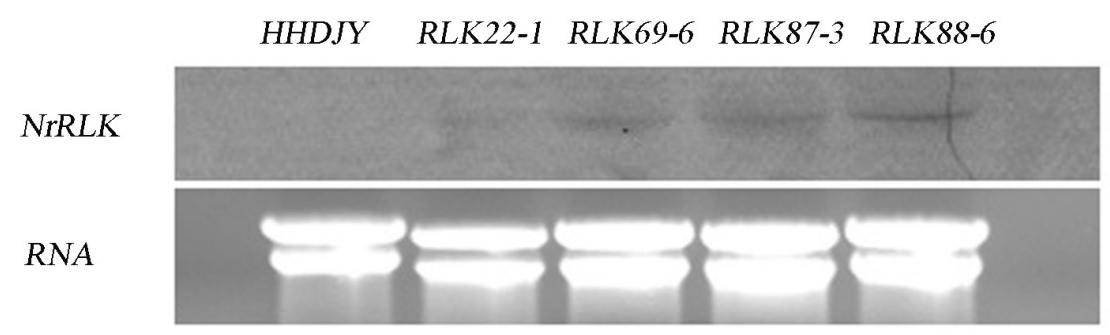

Figure 6. Northern analysis of NrSTK gene expression in transgenic plants. HHDJY Honghuadajinyuan. 
Disease resistance to $P$. parasitica var. nicotianae was evaluated in all transgenic lines (Table 1). RLK88-6 exhibited moderate resistance (similar to that of the Gexin 3 variety), while RLK22-1, RLK69-6, RLK72-6, and RLK76-6 had lower resistance levels, but still higher than the susceptible Honghuadajinyuan variety. The mean disease index for the transgenic lines RLK886, RLK69-6, and RLK22-1 was significantly higher than for Honghuadajinyuan, and similar to that of the resistant control variety, Gexin 3. It appeared that tobacco transgenic lines with higher expression levels of NrSTK showed a greater level of resistance to black shank. This correlation of gene expression level with resistance suggests that NrSTK is involved in plant defense reactions against $P$. parasitica var. nicotianae.

\begin{tabular}{|c|c|c|c|c|c|}
\hline \multirow[t]{2}{*}{ Line } & \multicolumn{4}{|c|}{ Disease index } & \multirow[t]{2}{*}{ Evaluation of resistance } \\
\hline & I & II & III & Mean & \\
\hline Honghuadajinyuan & 91.67 & 75.00 & 75.00 & $80.56^{A}$ & HS \\
\hline$R L K 78-3$ & 55.56 & 65.67 & 62.13 & $61.12^{A B}$ & S \\
\hline$R L K 72-6$ & 46.67 & 68.16 & 63.52 & $59.45^{\mathrm{AB}}$ & MS \\
\hline RLK 87-3 & 52.78 & 66.67 & 30.56 & $50.00^{\mathrm{AB}}$ & MS \\
\hline$R L K 76-6$ & 50.00 & 47.22 & 47.22 & $48.15^{\mathrm{AB}}$ & MS \\
\hline$R L K 22-1$ & 44.44 & 58.33 & 33.33 & $45.37^{\mathrm{B}}$ & MS \\
\hline$R L K 69-6$ & 52.78 & 41.67 & 41.67 & $45.37^{\mathrm{B}}$ & MS \\
\hline Gexin3 & 39.48 & 42.86 & 36.11 & $39.48^{\mathrm{B}}$ & MR \\
\hline$R L K 88-6$ & 22.22 & 27.78 & 33.33 & $27.78^{\mathrm{B}}$ & MR \\
\hline
\end{tabular}

\section{DISCUSSION}

The tobacco NrSTK gene reported here encodes a serine/threonine protein kinase with conserved motifs typical of protein kinases. NrSTK exhibited high sequence similarity with the tomato serine/threonine kinase Pto. Given that NrSTK was cloned using sequence information of a previously isolated $R G A$ that was induced by the black shank fungal pathogen, we reasoned that it might function in black shank resistance in tobacco. Overexpression of NrSTK in transgenic lines of the susceptible tobacco variety Honghuadajinyuan induced moderate resistance to black shank. Furthermore, the variations in levels of NrSTK expression in the different transgenic lines seemed to be correlated with the degree of resistance, strengthening the conclusion that NrSTK functions as a resistance gene in tobacco against black shank. Black shank is one of the most devastating diseases for global tobacco production. Understanding the molecular mechanisms of resistance to black shank should provide the necessary knowledge for genetically engineering resistance into commercial tobacco varieties to reduce losses due to black shank.

Research into black shank resistance is still at an early stage. However, screening of a suppression-subtractive hybridization library in tobacco identified the defense-related gene $h r s 203 \mathrm{~J}$ and a gene encoding a RING finger protein encoding that show strongly upregulated expression during incompatibility interactions (Chacon et al., 2009). RNAi-mediated silencing of expression of a glutathione transferase gene induces expression of defense response genes encoding $\beta-1,3-$ glucanase, superoxide dismutase (SOD) and MAPK kinase and improves resistance to black shank (Hernandez et al., 2009). Additionally, silencing of the serine protease inhibitor gene NmIMSP in Nicotiana megalosiphon decreases its resistance to black shank, while transient expression of NmIMSP in susceptible genotypes confers higher levels of resistance. This suggests that NmIMSP plays an important role in black shank resistance in tobacco (Silva et al., 2013). 
NrSTK was cloned from the wild tobacco $N$. repanda, which is immune to black shank. Hybrid incompatibility between $N$. repanda and commercial tobacco varieties has hampered both genetic studies of resistance mechanisms and breeding for resistance. Genetic resources for resistance to black shank in the varieties of tobacco currently in use for production are mainly derived from Florida 301 (Wernsman et al., 1974) and N. plumbaginifolia (Valleau et al., 1960); resistance in the former is controlled through multiple recessive genes and in the latter by a single resistance gene. The varieties currently used to produce commercial flue-cured tobacco are not completely immune to black shank, and the effects can still be seen when pathogen levels exceed a critical threshold. Therefore, to reduce losses in tobacco production, it will be essential to identify genetic resources that can be exploited for introducing immunity into commercial varieties. Cloning of the NrSTK gene provides one possible avenue for further research not only into the molecular mechanisms of black shank resistance but also for engineering more resistant varieties.

\section{Conflicts of interest}

The authors declare no conflict of interest.

\section{ACKNOWLEDGMENTS}

Research supported by the Yunnan Provincial Tobacco Company (\#07A03, \#2014YN06) and the State Tobacco Monopoly Administration [\#110201401006 (JY-06)].

\section{REFERENCES}

Brueggeman R, Druka A, Nirmala J, Cavileer T, et al. (2008). The stem rust resistance gene Rpg5 encodes a protein with nucleotide-binding-site, leucine-rich, and protein kinase domains. Proc. Natl. Acad. Sci. U. S. A. 105: 14970-14975.

Chacon O, Hernandez I, Portieles R, Lopez Y, et al. (2009). Identification of defense-related genes in tobacco responding to black shank disease. Plant Sci. 177: 175-180.

Deng Z and Gmitter FJ (2003). Cloning and characterization of receptor kinase class disease resistance gene candidates in Citrus. Theor. Appl. Genet. 108: 53-61.

Di Gaspero G and Cipriani G (2003). Nucleotide binding site/leucine-rich repeats, Pto-like and receptor-like kinases related to disease resistance in grapevine. Mol. Genet. Genomics 269: 612-623.

Gao Y, Xu Z, Jiao F, Yu H, et al. (2010). Cloning, structural features, and expression analysis of resistance gene analogs in tobacco. Mol. Biol. Rep. 37: 345-354.

Hernandez I, Chacon O, Rodriguez R, Portieles R, et al. (2009). Black shank resistant tobacco by silencing of glutathione S-transferase. Biochem. Biophys. Res. Commun. 387: 300-304.

Martin GB, Brommonschenkel SH, Chunwongse J, Frary A, et al. (1993). Map-based cloning of a protein kinase gene conferring disease resistance in tomato. Science 262: 1432-1435.

Morillo SA and Tax FE (2006). Functional analysis of receptor-like kinases in monocots and dicots. Curr. Opin. Plant Biol. 9: 460-469.

Morris ER and Walker JC (2003). Receptor-like protein kinases: the keys to response. Curr. Opin. Plant Biol. 6: $339-342$.

Nicholas KB, Nicholas HB and Deerfield DW (1997). GeneDoc: analysis and visualization of genetic variation. EMBNEW NEWS 4: 14.

Rance I, Fournier J and Esquerre-Tugaye MT (1998). The incompatible interaction between Phytophthora parasitica var. nicotianae race 0 and tobacco is suppressed in transgenic plants expressing antisense lipoxygenase sequences. Proc. Natl. Acad. Sci. U. S. A. 95: 6554-6559.

Salmeron JM, Oldroyd GE, Rommens CM, Scofield SR, et al. (1996). Tomato Prf is a member of the leucine-rich repeat class of plant disease resistance genes and lies embedded within the Pto kinase gene cluster. Cell 86: 123-33.

Silva Y, Portieles R, Pujol M, Terauchi R, et al. (2013). Expression of a microbial serine proteinase inhibitor gene enhances the tobacco defense against oomycete pathogens. Physiol. Mol. Plant. Pathol. 84: 99-106. 
Song WY, Wang GL, Chen LL, Kim HS, et al. (1995). A receptor kinase-like protein encoded by the rice disease resistance gene, Xa21. Science 270: 1804-1806.

Swiderski MR and Innes RW (2001).The Arabidopsis PBS1 resistance gene encodes a member of a novel protein kinase subfamily. Plant J. 26: 101-112.

Tamura K, Stecher G, Peterson D, Filipski A, et al. (2013). MEGA6: molecular evolutionary genetics analysis version 6.0. Mol. Biol. Evol. 30: 2725-2729.

Vallad G, Rivkin M, Ballejos C and Mcclean P (2001). Cloning and homology modeling of a Pto-like kinase family of common bean (Phaseolus vulgaris L.). Theor. Appl. Genet. 103: 1046-1058.

Valleau WD, Stokes GW and Johnson EM (1960). Nine years' experience with the Nicotiana longiflora factor for resistance to Phytophthora parasitica var. nicotianae in the control of black shank. Tob. Sci. 4: 92-94.

Warren RF, Henk A, Mowery P, Holub E, et al. (1998). A mutation within the leucine-rich repeat domain of the Arabidopsis disease resistance gene RPS5 partially suppresses multiple bacterial and downy mildew resistance genes. Plant Cell 10: $1439-1452$.

Wernsman EA, Matzinger DF and Powell NT (1974). Genetic investigations of intraspecific and interspecific sources of black shank resistance in tobacco. Tob. Sci. 18: 15-18. 